\title{
Paulo Freire e suas marcas no Vale do São Francisco
}

Francisco de Assis Silva

Professor assistente da Universidade do Estado da Bahia (Uneb). Doutor em Ciências da Comunicação pela Universidade de São Paulo (USP).

E-mail: diassis1974@gmail.com

Resumo: As contribuições de Paulo Freire para a implantação de um projeto de educação popular na Bahia podem ser verificadas em sua passagem pelo vale do São Francisco. Assim, este artigo mostra as marcas deixadas por Paulo Freire e os membros de sua equipe ao desenvolverem ações de formação continuada na Diocese de Juazeiro da Bahia, em Salvador, administrada pelo redentorista Dom José Rodrigues de Souza, na década de 1980. Objetivou-se analisar a prática e a vivência da política de educação popular e do projeto de comunicação social do bispado de D. José Rodrigues à luz das orientações de Paulo Freire. Os desdobramentos das ações realizadas nesse processo geraram novas possibilidades de construir conhecimentos, como a Educomunicação, que refletem na atualidade em espaços universitários, por exemplo.

Palavras-chave: educação; comunicação; educomunicação; conhecimento; alfabetização.
Abstract: Paulo Freire's contributions to the implementation of a popular education project in Bahia can be verified in his passage through the São Francisco valley. Thus, this article shows the marks left by Paulo Freire and his team members as they developed a work of continuing education in the diocese of Juazeiro da Bahia in the municipality of Salvador, administered by the redemptorist Dom José Rodrigues de Souza, in the 1980s. It aimed to analyze the practice and experience of the Popular Education Policy and the social communication project of the bishopric of D. José Rodrigues, carried out on Paulo Freire's guidelines. In this process, they generated new possibilities for the construction of knowledge, such as educommunication, that reflect today in spaces such as the university.

Keywords: education; communication; educommunication; knowledge; literacy. 


\section{INTRODUÇÃO}

O educador Paulo Freire fez a diferença por onde passou: despertou a esperança, incentivou o diálogo, promoveu a comunicação e revolucionou o processo educacional. No sertão do Vale do São Francisco, na Bahia, fez tudo isso ao aceitar o convite do redentorista Dom José Rodrigues, bispo da Diocese de Juazeiro da Bahia, para um trabalho de educação popular. Na década de 1980, Paulo Freire e sua equipe realizaram cursos, palestras e entrevistas e ofereceram orientações para a construção na região de Juazeiro de uma série de convicções, deixando um legado de mudança nas concepções associadas às relações sociais.

Este artigo foi motivado e se justifica pelo fato de buscar entender as ações desenvolvidas na Diocese de Juazeiro que, ao serem alicerçadas nas ideias e orientações de Paulo Freire, resultaram na criação de uma estrutura que compreende, além dos vários círculos de cultura e acervos bibliográficos, a importante reorganização social da população para a busca da garantia de seus direitos, tendo como elementos primordiais a produção, a gestão e a participação nos processos de educação e comunicação.

O acervo bibliográfico Dom José Rodrigues, hoje administrado pela Universidade do Estado da Bahia (Uneb) e organizado com o incentivo dado pelo professor Paulo Freire, foi a principal fonte de pesquisa deste estudo. Utilizou-se também, como instrumentos de coleta de dados, a observação, a descrição e a análise bibliográfica e documental. A análise de dados se desenvolveu como o fruto das articulações entre os dados coletados.

Os desdobramentos dessa intervenção repercutiram para além da Diocese, despertando o interesse de outros bispados - tempo em que um bispo ocupa a sede de uma diocese - e de instituições governamentais e não governamentais, que passaram a ter a pretensão de conhecer e participar do projeto de educação popular da Diocese.

\section{O CONTEXTO ENCONTRADO POR PAULO FREIRE NO VALE DO SÃO FRANCISCO}

A Diocese de Juazeiro se localiza no semiárido, na região nordeste do Brasil. O episcopado teve, geograficamente, o rio São Francisco banhando a maior parte dos municípios que o compõem e marcando os acontecimentos que fazem parte de sua história. O cenário é caracterizado por períodos intercalados de pouca umidade e de seca extrema, que impactam diretamente a história da região, marcada por dificuldades sociais e econômicas que podem ser medidas pela proximidade ou distância dos municípios das margens do rio. O modelo de desenvolvimento, implementado a partir de 1980 e ainda predominante alicerça-se na produção de energia elétrica por meio de grandes barragens, como a de Sobradinho, na Bahia, que favorecem a implantação de agricultura irrigada e de subsistência. Para a população, cabe o processo de aprendizagem 
de como conviver no semiárido, tema, aliás, próximo à atuação de Dom José Rodrigues, quando propõe fortalecer o projeto de educação popular da Diocese.

Acrescenta-se a este contexto o fato de que, no final da década de 1970, vivia-se no Brasil um regime político-ditatorial com um forte movimento social que desejava mudanças e acesso aos direitos civis. Neste contexto, em 1975, o padre José Rodrigues de Souza se torna bispo da Diocese de Juazeiro ao encontrar uma conjuntura social, política e econômica que desfavorecia a maior parte da população em vários aspectos, como saúde, educação, moradia e emprego. Diante da realidade encontrada, o bispo percebeu que algo precisava ser feito para mitigar as condições de vida impostas por uma gestão governamental com bases ditatoriais e excludentes.

Com a diocese sob a sua condução, e conhecendo os desafios que tinha pela frente, Dom José mobilizou os poucos padres e freiras disponíveis e começou a organizar o povo da diocese em comunidades eclesiais de base e a fazer uma gestão episcopal por meio da formação paulatina das pastorais sociais, a exemplo da pastoral da mulher marginalizada, dos pescadores, dos encarcerados, da juventude do meio popular, da saúde, da educação etc.

No final da década de 1970 e no início da de 1980, ao realizar uma assembleia com os representantes das comunidades de toda a diocese, no centro de treinamento de Carnaíba do Sertão, no interior de Juazeiro, Dom José decidiu que o próximo passo na organização dos leigos diocesanos seria dado com a criação de uma formação em educação política. Tal fato foi crucial para que fosse cogitada, e posteriormente concretizada, a participação direta do professor Paulo Reglus Neves Freire e sua equipe no projeto de educação popular no âmbito da Diocese de Juazeiro, no Vale do São Francisco.

Outro acontecimento marcante no Vale do São Francisco, na década de 1970, que instigou a necessidade de organizar o povo, foi a execução da construção da barragem de Sobradinho, localizada a $50 \mathrm{~km}$ da cidade de Juazeiro, mas que impactou toda a Diocese de Juazeiro, uma vez que os municípios de Casa Nova, Remanso, Sento Sé e Pilão Arcado foram atingidos diretamente com a inundação das cidades e diversos povoados. Cerca de 12 mil famílias foram deslocadas e, aproximadamente, 70 mil pessoas foram, em parte, indenizadas e realocadas em novas cidades, construídas para receber a população atingida pela obra. Esse processo gerou inúmeros problemas, principalmente de ordem social, pois as pessoas tiveram que reorganizar suas vidas, seus costumes e suas práticas de trabalho e de relações sociais. Sobre esse processo, Garcez afirma que:

A perspectiva de análise varia de acordo com a ótica do observador. Assim, aquela que reflete, prioritariamente, sobre questões econômicas responsáveis pela geração de progresso colide com a do estudioso preocupado com a situação do homem e com as alterações, para melhor ou pior, na sua condição de vida ${ }^{1}$.

1. GARCEZ, Angelina Nobre Rolim. Juazeiro: trajetória histórica. Juazeiro: Gutemberg, 1992, p. 292.
Tratava-se de um período de transição do regime ditatorial, iniciado em 1964, para um regime democrático, concretizado em 1985, com a eleição de Tancredo de Almeida Neves para a presidência da República do Brasil e com 
a Constituição Federal de 1988, que consolidou a mudança de regime após as contribuições de vários setores da sociedade civil organizada. Essa mudança histórica foi determinante na condução das ações e decisões para a realização do projeto de formação política e educacional que foi implantado na Diocese de Juazeiro com a contribuição de Paulo Freire e sua equipe.

Tanto o momento social e político quanto o fato de que a gestão de Dom José Rodrigues de Souza tinha suas bases alicerçadas principalmente na conferência de Medellín, de 1968, cujo tema era "A igreja na atual transformação da América Latina à luz do Concílio", e na Conferência de Puebla, de 1979, sobre a "Evangelização no presente e no futuro da América Latina" colaboram para a compreensão da ligação do trabalho episcopal da Diocese de Juazeiro com a proposta de formação desenvolvida por Paulo Freire, que visava à formação do conhecimento a partir de uma proposta de alfabetização. Sobre isso, Melo destaca que "o documento de Puebla traduz a certeza de que à opção pelos pobres, assumida pela hierarquia eclesiástica e respaldada pela prática libertadora das comunidades eclesiais de base, não importam atitudes conciliatórias frente às classes dominantes" ${ }^{2}$.

\section{A PROPOSTA E A MISSÃO DE PAULO FREIRE NO SERTÃO SANFRANCISCANO}

A Diocese de Juazeiro, que compreendia os municípios de Juazeiro, Sento Sé, Curaçá, Casa Nova, Remanso, Pilão Arcado e Campo Alegre de Lourdes, tinha uma população com um alto índice de analfabetismo, que impactava as vidas das pessoas de diversas formas, visto que impedia, inclusive, o acesso a conhecimentos que poderiam conduzi-las a um melhor entendimento sobre suas condições de vida.

Tal condição também atrapalhava Dom José Rodrigues de Souza no planejamento e na execução do seu projeto de uma vida eclesiástica de luta com os seus leigos. Assim, era urgente prosseguir e fortalecer uma política de educação popular - que já acontecia na Diocese - de forma mais incisiva, para, dessa forma, romper com as barreiras educacionais existentes e criar uma nova possibilidade de fortalecimento organizacional das pessoas por meio das comunidades eclesiais de base.

A proposta de uma formação política a partir de um programa de alfabetização estava em sintonia com o estatuto da Diocese de Juazeiro, que era registrada como Sociedade das Obras Sociais e Educativas (Sose). Nesse sentido, gradualmente foram realizadas ações para o desenvolvimento de um trabalho permanente de educação política. Para tanto, buscou-se, na pessoa de Paulo Freire e em suas ideias, a concretização do projeto de levar a população a conquista do direito a uma alfabetização contextualizada e construtora de conhecimentos. Sobre esse direcionamento dado pela Diocese de Juazeiro, Dom José Rodrigues conta: 


\section{comunicação \& educação • Ano XXVI • número 2 • jul/dez 2021}

2. MELO, José Marques de. Comunicação e libertação Petrópolis: Vozes, 1981, p. 13.

3. SILVA, Francisco de Assis. Educomunicação no sertão do São Francisco: 0 papel do acervo Dom José Rodrigues de Souza em Juazeiro da Bahia. 2020 Tese (Doutorado em Ciências da Comunicação) - Universidade de São Paulo, São Paulo, 2020, p. 110.

4. Ibidem, p. 111.
Em 1980, em Assembleia Diocesana, assumimos a "Educação Política”, permanente e não-partidária, como uma de nossas prioridades pastorais. Em 1981, publicamos a Cartilha "Política: a luta de um povo", que teve repercussão por todo o Brasil. Tendo Paulo Freire voltado do exílio em 1979, surgiu a ideia de trazê-lo à Diocese de Juazeiro para treinar monitores para a Educação Popular. Paulo Freire, que já ouvira falar da pastoral da Diocese, aceitou vir em 1983, passando uma semana conosco. Voltou, depois, em maio de 1984 e em abril de $1986^{3}$.

A decisão tomada em assembleia levou ao início da construção da proposta de realização das ações da política de educação popular pelos agentes pastorais da diocese e os membros da equipe do Professor Paulo Freire, que foram delineando as possíveis temáticas e os formatos de formadores necessários para o atendimento da necessidade de alfabetização a partir do contexto de vida dos membros da diocese.

A diocese tinha uma estrutura montada que atendia, naquele momento, a sete municípios. Por meio das paróquias e dos grupos eclesiásticos organizados de cada município, e sob a tutela de padres e freiras, os residentes desses locais foram os primeiros a participarem do projeto de educação popular, assumindo a função de monitores educacionais, ou seja, eram responsáveis por montar, coordenar e desenvolver as atividades dos ciclos de cultura.

Em uma nova assembleia, realizada em 1982, em que esteve presente Fátima Freire, foi exposta a proposta do projeto de educação popular com as primeiras ações de formação de monitores e com a oficialização das participações dos professores Paulo Freire e Ladislau Dowbor, em abril de 1983. Davam-se, assim, os primeiros passos em direção a estruturação das turmas de alfabetização almejada para a população. Silva descreve que Dom José Rodrigues informou que,

Conforme entendimento, iniciados pessoalmente com o prof. Paulo Freire, em fim de outubro do corrente ano, e continuados com a presença de Fátima Freire, na Assembleia Geral Diocesana, de 19 a 21 de novembro [de 1982], venho convidar ao Prof. Paulo Freire e ao Prof. Ladislau Dowbor para os primeiros passos de treinamento de monitores, a partir de 16 de abril de 1983, quando retornarei de São Paulo, após a Assembleia dos Bispos, em Itaici - SP.

O clérigo escreveu, no boletim Caminhar Juntos, sobre a ida de Paulo Freire e sua esposa, Elza Freire, a Juazeiro, em abril de 1983, para o treinamento de 25 monitores para a Campanha de Educação Popular, tecendo algumas considerações:

A Diocese tem procurado enfrentar as situações numa "opção decidida pelos pobres", procurando suscitar "Comunidades Eclesiais de Bases", onde o povo se reúne para viver e celebrar sua Fé e ter força de reivindicar seus direitos. Depois de alguns anos chegamos a duas conclusões: a) Necessidade de melhorar a situação econômica do povo. Enquanto não melhorarem as condições de produção, de trabalho, o nosso povo não terá condições de se libertar; b) Necessidade de alfabetização para o povo poder aproveitar dos materiais escritos, preparados pela Diocese. Diante de tudo isso é que convidamos o prof. Paulo Freire e sua equipe para colaborar conosco numa Campanha de Educação Popular, em nível 
diocesano, que abrangesse não só a alfabetização, mas também a economia popular. É isso que o prof. Paulo Freire e sua esposa, dona Elza, começaram a fazer, neste treinamento ${ }^{5}$.

Entre os registros das marcas de Paulo Freire no Vale do São Francisco, encontra-se uma entrevista concedida à jornalista Marta Luz Benevides, da Rádio Juazeiro, em 24 de abril de 1983, na primeira visita do educador à diocese. Na entrevista, Paulo Freire diz: "eu só pediria que guardassem esse papo, porque acho que, no fundo, eu fico contente de saber que eu estou vivo, eu estarei vivo em Juazeiro, mesmo depois de morto, com essa voz que fica aqui”.

O professor Paulo Freire fez sua segunda visita em maio de 1984 para dar continuidade à formação dos monitores. Neste momento, a campanha estava em pleno desenvolvimento da alfabetização do povo por meio dos "11 Círculos de Cultura: 3 na periferia de Juazeiro e 8 no interior da Diocese"7, segundo o boletim Caminhar Juntos. Os círculos de cultura foram criados com o intuito de concretizar o projeto de educação popular.

Um ponto marcante deste segundo momento em que Paulo Freire esteve presente na diocese foi uma palestra para os agentes das pastorais sociais, em que o educador levantou questionamentos e reflexões diversas, registradas por Dom José Rodrigues. Este cita, entre os pontos fortes da fala de Freire, a defesa do desenvolvimento de um trabalho educacional que seja também uma formação política e social.

O povo é proibido de saber como é oprimido e como criar coisa nova. Desnudar a realidade e aprender a ler a palavra e a escrever a palavra e ler a palavra. Leitura de mundo igual ao desnudamento da realidade. Revolução do mundo se faz pela leitura reta da palavra. O povo faz a revolução, toma a história nas mãos. Quando se lava as mãos diante do opressor, fica-se do lado do opressor ${ }^{8}$.

Paulo Freire voltou a Juazeiro uma terceira vez, em 1986, para mais uma etapa da formação dos monitores da educação popular e para participar de atividades planejadas pela equipe gestora do projeto na Diocese. O boletim Caminhar Juntos destacou que Freire,

Desta vez, fez treinamento de monitores de Educação Popular, em Carnaíba, nos dias 18 e 19 de abril, distrito de Juazeiro da Bahia, onde fica o Centro de Formação da Diocese. No dia 19, esteve no Centro Catequético, na cidade de Juazeiro para proferir palestra para o povo, principalmente para professores e alunos. No dia 21, deu entrevistas, por telefone, a rádio Juazeiro, gravou um programa "Semeando a Verdade" e deu as últimas orientações as equipes de Educação Popular da Diocese".

Dom José Rodrigues registrou no boletim que o legado da passagem de Paulo Freire pela diocese deixou as convicções de que "1. Educação é diálogo entre educador e educando; 2. Educação é um ato comunitário; 3. Educação não é uma etapa da vida, mas é um processo permanente; 4. Educação é um ato de liberdade e para a liberdade; 5 . Educação se faz na ação e na reflexão" ${ }^{10}$.
5. DIOCESE DE JUAZEIRO. Paulo Freire na diocese de Juazeiro. Caminhar Juntos - Boletim Informativo da Diocese de Juazeiro, Juazeiro, n. 79, p. 1-21, 1983, p. 1.

6. ARAÚJO, Joaquim Ribeiro de. Sobre a entrevista de Paulo Freire e seus bastidores. Revista Brasileira de Educação de Jovens e Adultos, Salvador, v. 2, n. 3, p. 8-25, 2014, p. 8.

7. DIOCESE DE JUAZEIRO. Educação popular segundo o método Paulo Freire. Caminhar Juntos-Boletim Informativo da Diocese de Juazeiro, Juazeiro, n. 87, p. 1-21, 1984a, p. 8.

8. SILVA, Francisco de Assis. Educomunicação... Op. cit., p. 113.

9. DIOCESE DE JUAZEIRO. Pela terceira vez, Paulo Freire volta à diocese de Juazeiro. Caminhar Juntos-Boletim Informativo da Diocese de Juazeiro, Juazeiro, n. 115, p. 1-21, 1986, p. 1.

10. Ibidem, p. 2. 
As marcas deixadas pelas três visitas do professor a Juazeiro demonstram a importância da intenção e da concretização de um projeto de educação popular, visto que acabou por se tornar uma política de educação popular na Diocese.

\section{DESBOBRAMENTOS DE UMA INTERVENÇÃO FREIRIANA}

A proposta de desenvolver um trabalho de educação política teve como um dos seus mais fortes momentos a campanha de alfabetização assessorada pelo professor Paulo Freire e sua equipe, resultando na estruturação de uma política de educação popular no âmbito da Diocese de Juazeiro que gerou reflexos dentro e fora dos limites diocesanos, com muitos desdobramentos. Para além das convicções, o projeto de educação popular desenvolvido pela igreja deixou marcas que podem ser vistas nos registros e na própria caminhada da Diocese.

Segundo Silva, a reorganização da biblioteca da diocese foi estimulada por Freire e é parte do legado desse projeto. Para Dom José Rodrigues:

Ficou da doutrina de Paulo Freire: modo democrático de dirigir a Diocese. Mais uma vez tenho ouvido de agentes pastorais: "o senhor nos dá liberdade para trabalhar". Viva, pois, Paulo Freire! Com o estímulo de Paulo Freire, fui montando a Biblioteca da Diocesana, hoje com 45 mil volumes, onde está a obra completa de Paulo Freire e de seus discípulos: Carlos Rodrigues Brandão e Moacir Gadotti ${ }^{11}$.

A biblioteca da Diocese de Juazeiro, a partir das orientações de Paulo Freire e sua equipe, passou a possuir um acervo tão expressivo que fez que o Instituto Cajamar, que tinha no seu conselho deliberativo, em 1987, Paulo Freire e Frei Betto, que conheciam o acervo constituído por Dom José Rodrigues de Souza, solicitasse a colaboração do bispo para a montagem de uma biblioteca para atender às demandas de formação do movimento sindical e político em São Paulo. Silva esclarece que:

A biblioteca da diocese de Juazeiro foi fundada em 19 de março de 1975 e inscrita no Instituto Nacional do Livro com o ${ }^{\circ} 17.752$ em 30 de outubro do mesmo ano. Foi idealizada e organizada por Dom José Rodrigues, tendo o estímulo de Paulo Freire na composição do acervo bibliográfico que serviu de apoio a projetos de educação e comunicação populares desenvolvidos pela diocese ${ }^{12}$.

Outro desdobramento que ressalta a importância da biblioteca foi ela ter servido de modelo para a montagem de outra com o mesmo nome, contendo aproximadamente 15 mil títulos, na Paróquia de Santo Antônio de Pilão Arcado, pertencente à Diocese de Juazeiro. A paróquia de Pilão Arcado teve bastante êxito no desenvolvimento dos projetos de educação popular segundo o método Paulo Freire.

Toda a estrutura da biblioteca e a atividade de suporte oferecida aos

11. SILVA, Francisco de Assis. Educomunicação..

Op. cit., p. 112-113.

12. Ibidem, p. 53. agentes pastorais e à sociedade em geral deixaram de fazer parte das políticas diocesanas de Juazeiro, abrindo espaço para a doação do acervo para a Uneb. Diante disso, em 4 de junho de 2013, o bispo de Juazeiro, Dom José Geraldo 
da Cruz, publicou uma nota no site da Diocese de Juazeiro sobre a biblioteca da Diocese, na qual dizia:

Foi constituída uma comissão de estudos que refletiu sobre o assunto [a biblioteca]. E, tendo consultado os Conselhos Presbiteral e de Pastoral, concluímos que chegou a hora de se dar um novo passo. Se a diocese sozinha não tinha a condição de realizar todas as transformações necessárias, deveríamos fazer parceria com um órgão público. Foi quando surgiu o interesse da Uneb, que abriu as suas portas para o diálogo e se dispôs a acolher a Biblioteca, colocando-a a disposição de quem quiser consultá-la. Foi assinado um termo de doação e a biblioteca terá o seu lugar de destaque, mantendo o seu nome: Biblioteca Dom José Rodrigues ${ }^{13}$.

A Uneb, campus Juazeiro, foi escolhida para receber a biblioteca da diocese por oferecer cursos de Comunicação Social, Pedagogia, Agronomia, Engenharia de Bioprocessos e Biotecnologia e o curso semipresencial de Administração e Direito, além das pós-graduações em Educação, Cultura e Território Semiárido, em Ecologia Humana e Gestão Socioambiental e em Agronomia: Horticultura Irrigada. Esses são cursos com características de construção de conhecimento que possuem afinidades com o teor oferecido pelo acervo da biblioteca da diocese, que funcionava, inclusive, como fonte de pesquisa dos professores, alunos e pesquisadores da universidade quando o acervo estava ainda sob a gestão da igreja. Em 20 de maio de 2013, o acervo da biblioteca da diocese foi doado, em caráter definitivo e gratuito, à Uneb, que o intitulou acervo Dom José Rodrigues de Souza.

O trabalho de educação popular repercutiu em outras cúrias. Em fevereiro de 1984, representantes da Diocese de Petrópolis (RJ) escreveram para a Diocese de Juazeiro sobre seu interesse em conhecer tal experiência educacional:

Tomamos conhecimento através do boletim diocesano "Caminhar Juntos", da Revista SEDOC e da Editora "Todos Irmãos" (SP), da experiência em andamento em sua diocese, de alfabetização de adultos de acordo com o Método Paulo Freire de Alfabetização de Adultos. Temos interesse de, neste ano de 1984, iniciar em âmbito paroquial uma caminhada neste sentido. Sabemos o quanto é valiosa essa vivência: de uma educação-conscientizada que procura valorizar a experiência de vida das pessoas que dela participam, que procuram eliminar a barreira educador educando, e que leva os educandos, uma vez alfabetizados, serem aqueles que serão os alfabetizadores dos companheiros ${ }^{14}$.

Na tese sobre Educomunicação no sertão do São Francisco, Silva registrou que, ao descrever a evolução do trabalho de educação popular desenvolvido na Diocese, em 1984, Dom José Rodrigues, ao fazer a devolutiva ao padre Francisco Milan da Diocese de Petrópolis, diz que "a Diocese de Juazeiro possui 11 círculos de cultura”. Em 1986, em carta a Beatriz Costa, da editora Nova, ao falar do recebimento dos cadernos de educação popular, cita a existência de dois núcleos de educação popular, sendo que um deles já tinha 16 círculos de cultura. Em 1993, em carta ao Comitê Nobel Norueguês, Dom José Rodrigues diz que "a Diocese tem 30 círculos de cultura”. Por fim, o boletim Caminhar Juntos de 1996 relata a existência de 33 círculos de cultura, com quase 600 alfabetizados $^{15}$.
13. CRUZ, Dom José Geraldo da. Biblioteca Dom José Rodrigues. Diocese de Juazeiro, Juazeiro, 12 jun. 2013. Disponível em: http://diocesedejuazeiro.blogspot. com/2013/06/biblioteca-dom-jose-rodrigues.html. Acesso em: 20 nov. 2019.

14. SILVA, Francisco de Assis. Educomunicação... Op. cit., p. 114.

15. Ibidem, p. 114. 


\section{comunicação \& educação • Ano XXVI • número 2 • jul/dez 2021}

A Uneb fundou, anos mais tarde, a Faculdade de Filosofia, Ciências e Letras de Juazeiro (FFCLJ), que fornecia o curso de Pedagogia com habilitação em Educação de Jovens e Adultos. Alguns dos professores da faculdade participaram da formação oferecida por Paulo Freire e atuaram como monitores da política de educação popular desenvolvida na Diocese de Juazeiro na década de 1980. O Departamento de Ciências Humanas de Juazeiro possui, no currículo do curso de Pedagogia, um núcleo de Educação de Jovens e Adultos que oferece disciplinas e projetos para a formação de pedagogos com forte influência das teorias de Paulo Freire.

A Diocese de Juazeiro, com o intuito de disseminar a política de educação popular em todo o seu território, fundou e colocou em funcionamento várias escolas, em parceria com o governo estadual. Nessas escolas, os ciclos de cultura foram vivenciados à luz do método de Paulo Freire. No boletim Caminhar Juntos, Dom José escreveu que:

Não deixa de ser interessante o convênio que a Diocese mantém com a Secretaria de Educação. Em vez do Governo da Bahia repassar dinheiro para Diocese aplicar na educação, acontece o contrário, a Diocese cede 4 prédios com 21 salas de aula, oferecendo ocasião para estudar 1520 alunos $^{16}$.

A Diocese de Juazeiro, por meio de sua razão social - Sose -, também buscou implementar a sua política de educação popular mediante convênios com a Fundação Educar, com a qual aprovou projetos de financiamento para a criação de novos ciclos de cultura no âmbito diocesano, a partir de 1985, devido à extinção do Movimento Brasileiro de Alfabetização (Mobral). Dessa forma, constata-se que o trabalho da diocese era, de fato, de uma política de educação popular que acabava transpondo o âmbito eclesiástico, apesar de continuar sob a coordenação de padres e leigos ligados à Igreja Católica.

A política de educação popular da diocese teve como desdobramento a criação de um grande projeto de comunicação social com a rede de correspondentes populares e as equipes paroquiais de comunicação, tendo como pilares fundamentais: a democracia nos processos, o diálogo permanente, a participação em todos os níveis das ações e a construção coletiva de conhecimentos. Tais fundamentos eram defendidos por Paulo Freire e amplamente estudados e vivenciados nas ações educacionais desenvolvidas pela diocese. Nessa linha de pensamento, o desenvolvimento dos trabalhos foi estabelecido pela Pastoral

17. DIOCESE DE JUAZEIRO. Caminhar Juntos - Boletim Informativo da Diocese de Juazeiro, Juazeiro, n. 189, p. 1-18, 1995, p. 14.

16. DIOCESE DE JUA. ZEIRO. Escolas mantidas pela diocese. Caminhar Juntos - Boletim Informativo da Diocese de Juazeiro, Juazeiro, n. 99 p. $1-23,1984 b$, p. 12. das Comunicações Sociais, tendo, como registrado no boletim Caminhar Juntos, o objetivo de

Dar vez e voz às camadas mais sofridas da sociedade: pescadores, assalariados, trabalhadores, mulheres e desempregados, através da participação destes, ativamente, nos diversos formatos de comunicação (programas de rádio, altofalantes, vídeos e boletins), para que sejam veiculadas as denúncias de opressão, as reivindicações, os direitos sociais e a valorização às expressões culturais e a organização popular como instrumentos de luta e despertar do senso crítico $^{17}$. 
Atualmente, os mesmos fundamentos trabalhados no projeto de educação popular da Diocese de Juazeiro aparecem no campo da Educomunicação, que tem no professor Paulo Freire um dos seus principais teóricos e no professor Ismar Soares o mérito da coordenação das ações que, junto ao Núcleo de Comunicação e Educação da Universidade de São Paulo (NCE-USP), ressemantizaram, em 1999, o termo Educomunicação como sendo:

Um campo de ação emergente na interface entre os tradicionais campos da educação e da comunicação, apresenta-se, hoje, como um excelente caminho de renovação das práticas sociais que objetivam ampliar as condições de expressão de todos os seguimentos humanos, especialmente da infância e da juventude ${ }^{18}$.

O trabalho desenvolvido pela Diocese de Juazeiro a partir das ideias e das teorias de Paulo Freire, colocadas na práxis de uma política de educação popular e em um projeto de comunicação social, rendeu a Dom José Rodrigues a defesa, na tese de Silva ${ }^{19}$, do título de precursor da Educomunicação no vale do São Francisco, devido à presença de indicadores educomunicativos em todos os processos das atividades desenvolvidas na diocese.

No curso de Pedagogia do Departamento de Ciências Humanas da Uneb, que funciona na área da Diocese de Juazeiro, existe um núcleo de educação e comunicação no qual as teorias de Paulo Freire e o campo da Educomunicação são objetos de estudos e projetos de ensino, pesquisa e extensão. Ademais, a experiência da Diocese é tida por esse núcleo como elemento de referência e reflexão para a construção de novos conhecimentos. Tal reconhecimento e evolução demonstram a importância de que se dê continuidade a este trabalho que, de fato, consolidou-se como uma política de educação popular.

\section{CONSIDERAÇÕES FINAIS}

O desenvolvimento de uma campanha de alfabetização como parte de uma política de educação popular, com a assessoria de Paulo Freire e sua equipe, no período de 1983 a 1986, na realização das várias formações, no acompanhamento do processo e no fornecimento de materiais, deixou marcas no Vale do São Francisco que continuam a gerar movimentações no âmbito educacional.

Como desdobramento da política de educação popular, realizou-se um projeto de comunicação popular com duas linhas de ações: a rede de correspondentes populares e as equipes paroquiais de comunicação, cujas atividades se encontravam sintonizadas com muitos dos indicadores educomunicativos vivenciados nas ações educacionais da diocese.

Foi fundamental, nesse processo, a criação da biblioteca da diocese, que, posteriormente, passou a ser o acervo Dom José Rodrigues, que serviu de modelo e inspiração para a criação de outros acervos bibliográficos por possuir um vasto material, este reunido sob a orientação de Paulo Freire e sua equipe de formação. $O$ acervo foi utilizado como um instrumento de articulação e suporte das ações educacionais e comunicativas.
18. SOARES, Ismar de Oliveira. Educomunicação: 0 conceito, o profissional, a aplicação - contribuições para a reforma do ensino médio. São Paulo: Paulinas, 2011, p. 15.

19. SILVA, Francisco de Assis. Educomunicação... Op. cit. 
O uso social e pastoral do material herdado do projeto de educação popular continua a dar contribuições aos processos de ensino, pesquisa e extensão no Vale do São Francisco, mais especificamente nos trabalhos desenvolvidos pela Uneb, detentora do acervo da antiga biblioteca da Diocese de Juazeiro a partir de 2013, agora conhecido como acervo Dom José Rodrigues de Souza, uma homenagem ao bispo que atuou durante 28 anos na diocese e que tinha a educação popular como uma de suas linhas de ação.

As marcas deixadas por Paulo Freire são referências e inspirações para a criação e a execução de novos projetos nos âmbitos das pastorais eclesiásticas, das organizações não governamentais e das instituições educacionais no Vale do São Francisco, uma vez que geraram os mais variados desdobramentos, por exemplo, a inserção do campo da Educomunicação como um novo paradigma a ser vivenciado nas relações educativas e comunicativas das instituições.

Diante disso, o artigo evidenciou que as marcas que o professor Paulo Reglus Neves Freire deixou no Vale do São Francisco são profundas e favorecem o entendimento da importância de sua atuação no projeto para a mudança da conjuntura social de Juazeiro e da vida das pessoas naquela época. Ainda, o método freireano contribui para o desenvolvimento, a partir da experiência na diocese, de estudos sobre novas experiências que favoreçam a construção de políticas educacionais capazes de garantir o acesso à construção do conhecimento e, consequentemente, os direitos de todos enquanto cidadãos.

\section{REFERÊNCIAS BIBLIOGRÁFICAS}

ARAÚJO, Joaquim Ribeiro de. Sobre a entrevista de Paulo Freire e seus bastidores. Revista Brasileira de Educação de Jovens e Adultos, Salvador, v. 2, n. 3, p. 8-25, 2014.

CRUZ, Dom José Geraldo da. Biblioteca Dom José Rodrigues. Diocese de Juazeiro, Juazeiro, 12 jun. 2013. Disponível em: http://diocesedejuazeiro. blogspot.com/2013/06/biblioteca-dom-jose-rodrigues.html. Acesso em: 20 nov. 2019.

DIOCESE DE JUAZEIRO. Educação popular segundo o método Paulo Freire. Caminhar Juntos - Boletim Informativo da Diocese de Juazeiro, Juazeiro, n. 87, p. 1-21, 1984a.

DIOCESE DE JUAZEIRO. Escolas mantidas pela diocese. Caminhar Juntos Boletim Informativo da Diocese de Juazeiro, Juazeiro, n. 115, p. 1-21, 1984b.

DIOCESE DE JUAZEIRO. Pastoral das comunicações. Caminhar Juntos Boletim Informativo da Diocese de Juazeiro, Juazeiro, n. 189, p. 1-18, 1995.

DIOCESE DE JUAZEIRO. Paulo Freire na diocese de Juazeiro. CaminharJuntosBoletim Informativo da Diocese de Juazeiro, Juazeiro, n. 79, p. 1-21, 1983. 
DIOCESE DE JUAZEIRO. Pela terceira vez, Paulo Freire volta à diocese de Juazeiro. Caminhar Juntos - Boletim Informativo da Diocese de Juazeiro, Juazeiro, n. 115, p. 1-21, 1986.

GARCEZ, Angelina Nobre Rolim. Juazeiro: trajetória histórica. Juazeiro: Gutemberg, 1992.

MELO, José Marques de. Comunicação e libertação. Petrópolis: Vozes, 1981. SILVA, Francisco de Assis. Educomunicação no sertão do São Francisco: o papel do acervo Dom José Rodrigues de Souza em Juazeiro da Bahia. 2020. Tese (Doutorado em Ciências da Comunicação) - Universidade de São Paulo, São Paulo, 2020.

SOARES, Ismar de Oliveira. Educomunicação: o conceito, o profissional, a aplicação - contribuições para a reforma do ensino médio. São Paulo: Paulinas, 2011. 